\title{
Efficacy of SSRIs on cognition of Alzheimer's disease patients treated with cholinesterase inhibitors
}

\author{
Luca Rozzini, ${ }^{1,2}$ Barbara Vicini Chilovi, ${ }^{1,2}$ Marta Conti, ${ }^{1}$ Erik Bertoletti, \\ Marina Zanetti, ${ }^{1}$ Marco Trabucchi ${ }^{2}$ and Alessandro Padovani ${ }^{1}$ \\ ${ }^{1}$ Department of Neurology, University of Brescia, Italy \\ ${ }^{2}$ Geriatric Research Group, Brescia, Italy.
}

ABSTRACT

Background: This study examines the joint effect on cognition of selective serotonin re-uptake inhibitors (SSRIs) and cholinesterase inhibitors (AChEIs) in depressed patients affected by Alzheimer's disease (AD) living at home.

Methods: The study was conducted in two different outpatient neurological clinics. 338 patients with probable $\mathrm{AD}$ were treated with ChEis (donepezil, rivastigmine and galantamine) as per the clinician's judgment and were observed for nine months. At study entry, participants underwent a multidimensional assessment evaluating cognitive, functional and psychobehavioral domains. All patients were evaluated at baseline, after one (T1), three (T2) and nine months (T3). Patients were grouped in three different categories (patients not depressed and not treated with SSRIs, patients depressed and treated with SSRIs, and patients depressed but not treated with SSRIs).

Results: At baseline 182 were diagnosed as not depressed and not treated with SSRIs, 66 as depressed and treated with SSRIs, and 90 as depressed but not treated with SSRIs. The mean change in MMSE score from baseline to nine months showed that depressed patients not treated worsened in comparison with those not depressed and not treated with SSRIs (mean change $-0.8 \pm 2.3$ vs $0.04 \pm 2.9 ; \mathrm{p}=0.02$ ) and patients depressed and treated with SSRI (mean change $-0.8 \pm 2.3$ vs $0.1 \pm 2.5 ; \mathrm{p}=0.03$ ).

Conclusions: In AD patients treated with AChEIs, SSRIs may exert some degree of protection against the negative effects of depression on cognition.

Key words: Alzheimer disease, depression, cholinesterase inhibitors, SSRI

\section{Introduction}

Alzheimer's disease (AD) is a common disorder whose psychosocial impact increases as the proportion of elderly people in the population grows (Suh and Shah., 2001). To date, the most successful therapeutic approaches have involved cholinesterase inhibitors (AChEIs) (Bellelli et al., 2005; Rozzini et al., 2005).

In elderly subjects depression is a prevalent and serious disorder that is associated with reduced quality of life and increased morbidity and mortality (Blazer et al., 1987). In elderly subjects and in elderly patients with medical illness or in residential

Correspondence should be addressed to: Luca Rozzini, MD, Department of Neurology, University of Brescia, Piazzale Spedali Civili 1, 25100 Brescia, Italy. Phone: +39030 3995632; Fax: +39030 3849205. Email: Irozzini@iol.it. Received 28 Jan 2009; revision requested 4 Mar 2009; revised version received 27 Apr 2009; accepted 28 Apr 2009 First published online 25 June 2009. settings the prevalence of depression ranges from $7 \%$ to $42 \%$ (Bruce et al., 1994). Several placebocontrolled studies on selective serotonin re-uptake inhibitors (SSRIs) have demonstrated their efficacy in improving symptoms of depression (Rapaport et al., 2003).

Since approximately $25-40 \%$ of AD patients may develop depressive symptoms and since a growing body of research has found cognitive impairment to be a common clinical feature of late life depression (Niederehe et al., 1995), our aim is to investigate pharmacological strategies to improve and stabilize cognitive functioning in late-life depression and minimize progression of cognitive impairment. To this end we evaluated the role on cognition of combining selective SSRIs with medications used in $\mathrm{AD}$ (donepezil, rivastigmine and galantamine), hypothesizing a joint effect that may delay cognitive deterioration. 


\section{Methods}

Three hundred and sixty-eight Alzheimer patients were enrolled consecutively in two different outpatient clinics (Alzheimer Evaluation Units, UVA, Brescia, Northern Italy) between January 2003 and January 2006. All patients with AD met the National Institute of Neurological and Communicative Disorders and Stroke Alzheimer's Disease and Related Disorders (NINCDS-ADRDA) criteria for probable $\mathrm{AD}$ (McKhann et al., 1984), as judged by an experienced AD research clinician. Diagnostic evaluation included: demographic and clinical features, medical history, physical and neurological examination, neuropsychological testing, routine blood tests (including thyroid hormones, vitamin B12 level, and serological tests for syphilis), and neuroimaging with brain computerized tomography. Duration of the disease was considered at the time of onset of memory disturbances that exceeded the episodic forgetfulness that might have been regarded as usual for the patient, or of other disturbances (language, praxis, orientation, visuospatial skills) that were clearly related to the disease.

At baseline, participants were assessed by a neuropsychologist using the Mini-mental State Examination (MMSE; Folstein et al., 1975), the Alzheimer's Disease Assessment Scale ADAS-Cog (Fioravanti et al., 1994) and the global Clinical Dementia Rating (CDR; Hughes et al., 1982) to evaluate the global cognitive function; the Instrumental Activities of Daily Living (IADL; Lawton and Brody, 1969) and Basic Activities of Daily Living (BADL; Katz et al., 1970) to detect impairment in activity functions; the Geriatric Depression Scale (GDS) 15 items (Sheikh and Yesavage, 1986) to study the presence of depressive symptoms, and the Neuropsychiatry Inventory (NPI; Cummings et al., 1994), to study psychobehavioral disturbances. Every concomitant illness and treatment was recorded.

Patients were classified as depressed through clinical and neuropsychiatric investigation with DSM-IV criteria for depression in Alzheimer's disease (American Psychiatric Association, 1994). All subjects and their caregivers were asked, by the clinic doctor, about the symptoms of depressed mood, decrease of interest or pleasure, changes in appetite, changes in sleep, loss of energy, feelings of guilt, worthlessness or that life was not worth living, difficulty in concentrating, and psychomotor agitation or retardation.

From 368 patients recruited, 30 patients were excluded from the analysis during the period of observation: 11 for low compliance (the patients changed to another clinic or they did not want to make the periodic visits), nine for nausea or headache, four for seizures and six patients for institutionalization. No statistical differences on demographic, clinical and neuropsychological characteristics have been observed among the two groups (analyzed vs excluded).

At the start of the study, patients received donepezil $(\mathrm{n}=227 ; 67 \%)$, rivastigmine $(\mathrm{n}=69$; $20 \%)$ and galantamine $(\mathrm{n}=42 ; 13 \%)$ as per the clinician's judgment; patients took donepezil $5 \mathrm{mg}$ per day, rivastigmine $1.5 \mathrm{mg} / \mathrm{bid}$ per day and galantamine $4 \mathrm{mg} / \mathrm{bid}$ per day. The effects of treatment were investigated at 1 (T1), 3 (T2) and 9 (T3) months. At each clinical visit the dose of AChEIs was increased according to the investigator's judgment. If the increased dose was not tolerated, it was decreased to the previous welltolerated dose. All changes were recorded. Patients were allowed to attend the clinic for any problem or adverse effect. At three months the mean dose was $7.5 \mathrm{mg} \pm 2.5$ of donepezil, $6.7 \pm 2.1 \mathrm{mg}$ of rivastigmine and $11.8 \pm 4.4 \mathrm{mg}$ of galantamine.

To evaluate the role on cognition of combining SSRIs with AChEIs we grouped three different categories of patients: patients not depressed and not treated with SSRIs at baseline, patients depressed and treated with SSRIs at baseline, and patients depressed but not treated with SSRIs. In our sample there were no patients treated with SSRI but not depressed. All patients already taking SSRIs at baseline did not discontinue the therapy during the period of observation (nine months).

Although the consensus for treatment of $\mathrm{AD}$ patients addresses the importance of additionally treating behavioral symptoms, the lack of clear guidelines indicating when and how to treat depressive symptoms has led us to decide the prescription of antidepressants in accordance with a clinical global judgment.

The study was approved by institutional review boards and written informed consent was obtained from both the patients and their responsible caregivers.

\section{Statistical analysis}

Statistical analysis was performed with the Statistical Package for the Social Sciences (SPSS, 2002). Descriptive statistics at baseline were performed on socio-demographic, clinical, neuropsychological, functional and psycho-behavioral characteristics. Quantitative variables were expressed as mean \pm standard deviation. Continuous variables were assessed using analysis of variance (ANOVA) models and the $\chi^{2}$ test for dichotomous ones. Posthoc comparisons, adjusted using the Bonferroni correction, were used to make comparisons between 
Table 1. Sociodemographic and clinical characteristics of Alzheimer's patients at baseline treated with cholinesterase inhibitors and divided in three groups on the basis of depression and SSRI treatment

\begin{tabular}{|c|c|c|c|c|c|c|c|c|c|}
\hline & \multicolumn{3}{|c|}{$\begin{array}{l}\text { NOT DEPRESSED } \\
\text { NOT TREATED } \\
\text { WITH SSRI } \\
\mathrm{N}=182\end{array}$} & \multicolumn{3}{|c|}{$\begin{array}{l}\text { DEPRESSED } \\
\text { TREATED WITH } \\
\text { SSRI } \\
\mathrm{N}=66\end{array}$} & \multicolumn{3}{|c|}{$\begin{array}{l}\text { DEPRESSED NOT } \\
\text { TREATED WITH } \\
\text { SSRI } \\
\mathrm{N}=90\end{array}$} \\
\hline & MEAN & SD & $\%$ & MEAN & SD & $\%$ & MEAN & SD & $\%$ \\
\hline Age (years) & 76,7 & 6,7 & & 75,7 & 7,6 & & 75,9 & 7,2 & \\
\hline Sex (female) & & & 63 & & & 81 & & & 71 \\
\hline Education (years) & 5,9 & 3,1 & & 5,5 & 2,3 & & 5,7 & 2,8 & \\
\hline Duration of the symptoms (months) & 25,1 & 13,5 & & 23,5 & 12,7 & & 26,5 & 13,2 & \\
\hline $\mathrm{CDR}$ & 0,9 & 0,4 & & 0,8 & 0,4 & & 0,8 & 0,3 & \\
\hline MMSE & 20,3 & 4,4 & & 20,1 & 4,3 & & 20,1 & 4,6 & \\
\hline IADL (functions maintained) & 4,4 & 2,3 & & 4,7 & 2,2 & & 4,4 & 2,3 & \\
\hline ADL (functions maintained) & 5,2 & 1,3 & & 5,3 & 1,1 & & 5,0 & 1,4 & \\
\hline ADAS Cog & 17,8 & 8,8 & & 16,4 & 9,3 & & 17,5 & 10,9 & \\
\hline NPI total & $12,9^{* \circ}$ & 11,4 & & $21,7^{*}$ & 14,2 & & $21,6^{\circ}$ & 15,5 & \\
\hline MMSE mean change GDS & $2,1^{\circ}$ & 1,4 & & $8,1^{\circ *}$ & 2,8 & & $7,3^{\circ *}$ & 2,3 & \\
\hline Number of drugs & $0,2^{\circ}$ & 0,4 & & $1,6^{\circ *}$ & 0,6 & & $0,4^{*}$ & 0,6 & \\
\hline
\end{tabular}

${ }^{\circ *} \mathrm{p}<0.05$ values are based on ANOVA model with post hoc comparisons, adjusted using the Bonferroni correction.

MMSE: Mini-mental State Examination (0-30); ADAS Cog: Alzheimer Disease Assessment Scale, cognitive part (0-70); IADL: Instrumental Activities Daily Living (0-8); BADL: Basic Activities of Daily Living (0-6); CDR: Clinical Dementia Rating Scale (0-5); NPI: Neuropsychiatry Inventory (0-144); GDS: Geriatric Depression Scale (0-15); ApoE: Apolipoprotein E

group means at baseline. The significance of change in three groups (patients not depressed and not treated with SSRIs at baseline, patients depressed and treated with SSRIs at baseline, and patients depressed but not treated with SSRIs) from baseline to 3 and 9 months for MMSE was evaluated through General Linear Model repeated measures (GLM). All tests were 2-tailed at a probability level of 0.05 .

Potential confounders (age, sex, education and the total GDS score) were evaluated by entering their values as covariates.

\section{Results}

A total of 338 patients with mild to moderate Alzheimer's disease were evaluated for nine months. At baseline, 182 of these were diagnosed as not depressed and not treated with SSRI, 90 were classified as depressed and not treated with SSRI and 66 patients were depressed and treated with SSRI. Of the last group, 38 reported use of citalopram (from 10 to $20 \mathrm{mg}$ per day), 15 of escitalopram (from 5 to $10 \mathrm{mg}$ per day), 10 of setraline (50 mg per day), two of fluoxetine (20 $\mathrm{mg}$ per day) and one of paroxetine $(20 \mathrm{mg}$ per day). As summarized in Table 1 , there were no statistically significant baseline differences between the three groups in terms of sociodemographic characteristics. As expected, not treated and treated (probably not sufficiently because treated by a family doctor not specialist) depressed patients had significantly higher mean NPI and GDS scores and the group of depressed patients treated with SSRIs took a significantly higher number of drugs than the other two groups.

At three months (Figure 1), a cognitive improvement was observed from baseline in non depressed patients not treated with SSRIs (T2 mean MMSE $20.9 \pm 5.2$ vs baseline $20.3 \pm 4.4$; $\mathrm{p}=0.005)$, in depressed patients treated with SSRIs (T2 mean MMSE $20.8 \pm 5.3$ vs baseline $20.1 \pm 4.3 ; \mathrm{p}=0.005)$ and a cognitive stabilization in depressed patients not treated with SSRIs (T2 mean MMSE $20.7 \pm 5.3$ vs baseline $20.6 \pm 4.6$; $\mathrm{p}=$ NS). At nine months, cognitive stabilization from baseline characterized non depressed patients not treated with SSRI (T3 mean MMSE 20.4 \pm 5.0 vs baseline $20.3 \pm 4.4$ ) and depressed patients treated with SSRI (T3 mean MMSE 20.2 \pm 5.1 vs baseline $20.1 \pm 4.3$ ). In contrast, a cognitive worsening from baseline was observed in depressed patients not treated with SSRIs (T3 mean MMSE $19.8 \pm 5.0$ vs baseline $20.6 \pm 4.6$ ). Finally, the mean change in MMSE score from baseline to nine months demonstrated that depressed patients not treated worsened when compared with patients not depressed and not treated with SSRIs and with patients depressed and treated with SSRIs (mean change $-0.8 \pm 2.3$ vs $0.04 \pm 2.9$ vs $0.1 \pm 2.5$; $\mathrm{p}<0.05$ respectively). 


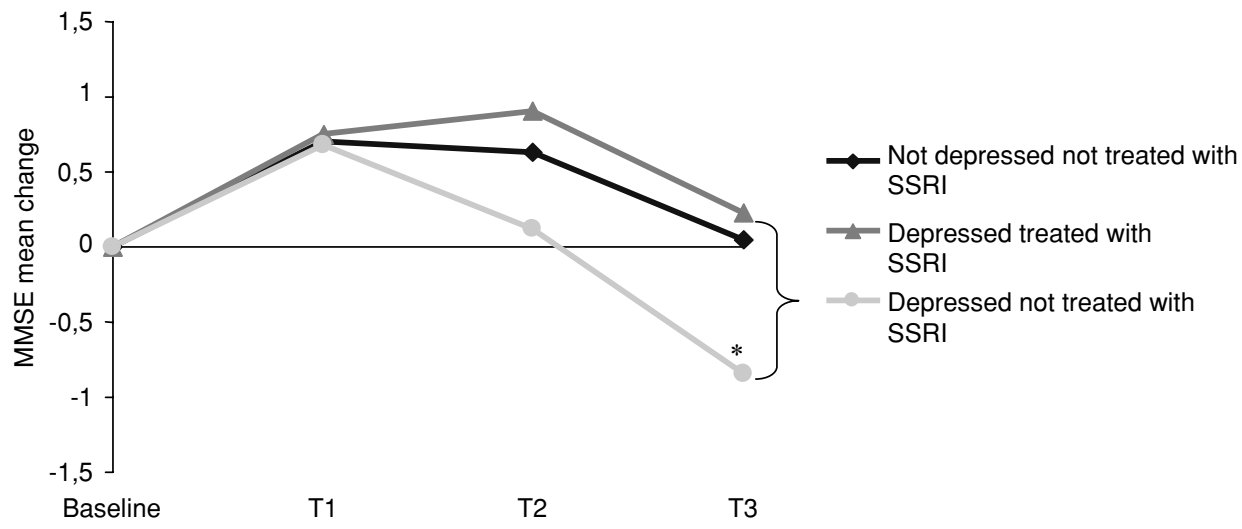

Figure 1. Mean change of MMSE after 1, 3 and 9 months of treatment with cholinesterase inhibitors and divided in three groups on the basis of depression and SSRI treatment at baseline.

The significance of change in three groups from baseline to 1, 3, 9 months for MMSE was evaluated using the General Linear Model (GLM). * Mean change of MMSE in depressed patients not treated with SSRI versus other two different groups; $\mathrm{p} \leq 0.05$.

\section{Discussion}

We observed that use of SSRI medications in people with AD treated with AChEIs may exert some degree of protection against the negative effect of depression on cognition.

A growing body of research has found cognitive impairment to be a common clinical feature of late life depression (Niederehe et al., 1995). The cognitive impairment appears to be associated with alterations in serotonergic neurotransmission implicated both directly and through interaction with central cholinergic pathways (Kalayam and Alexopoulos, 1999).

Several findings have suggested that SSRIs may improve different aspects of cognition. Rocca and colleagues (2005) suggest that citalopram may improve cognitive disturbances induced by minor depressive disorder and subsyndromal depressive symptomatology in elderly patients. Other authors demonstrate that low dose citalopram is useful for the treatment of memory deficits and that acute administration of this drug, through the augmentation of serotonergic neurotransmission, facilitates memory consolidation and enhances long-term memory performance (Harmer et al., 2002). Escitalopram also has been demonstrated to improve cognitive efficiency in complex attention, short- and long-term recall of contextual information, and short-term recall of visual information (Savaskan et al., 2007). Improvement of cognition with SSRIs was also obtained utilizing sertraline (Constant et al., 2005), fluoxetine (Levkovitz et al., 2002) and paroxetine (Cassano et al., 2002).

To date, literature analysis does not clarify if the combined effect of SSRIs and AChEIs is synergic or independent (Pelton et al., 2007).
We hypothesize the presence of two potential mechanisms by which antidepressants affect cognition in depression: (i) a direct effect caused by the pharmacologic action of the drugs on specific neurotransmitters, and (ii) a secondary effect caused by improvement of depression. The first hypothesis is sustained by studies demonstrating that SSRIs change the intracellular iron distribution that would be predicted to limit indirectly amyloid precursor protein (APP) expression (e.g. Morse et al., 2004) and amyloid beta peptide secretion that are involved in the pathogenesis of AD.

In this regard, Pákáski and colleagues (2005) indicate that SSRIs are able to interfere with the APP metabolism in vitro and assert that antidepressant medication might be beneficial in AD therapy. The second hypothesis is supported by Vythilingam and colleagues (2004) who demonstrated that treatment with antidepressants significantly improved memory and depression, independently of detectable brain structural changes.

In a recent pilot study, Pelton and colleagues (2008) proposed that since serotonin deficits are known to be associated with depression that modulates cognitive performance and since the beneficial effects of cholinesterase inhibitors suggest that cholinergic neurotransmitter deficits contribute to the cognitive impairment in $\mathrm{AD}$, the cognitive improvements by combining antidepressants and donepezil may involve independent neurotransmitter systems.

A limitation of this observational study includes the duration of treatment with SSRIs before the baseline; because the SSRI was administered by the family doctor we know the initiation of treatment only in a small group of patients. Another limitation relates to the decision not to treat with SSRIs a number of patients with depressive symptoms. 
The decision is supported by data demonstrating the possible effect of AChEIs on these symptoms (Rozzini et al., 2007). This option was adopted with the consent of the caregivers in order to reduce the number of drugs prescribed to their relatives.

The results support the clinical experience that treatment of depression with SSRIs in AD patients who are already on AChEIs might have a slightly better outcome in cognitive measures.

\section{Conflict of interest}

None.

\section{Description of authors' roles}

Luca Rozzini analyzed the data, reviewed the literature and wrote the paper. Barbara Vicini Chilovi, Marta Conti, Erik Bertoletti and Marina Zanetti recruited the study subjects, undertook the administration of multidimensional assessment and assisted with data analysis and the writing of the paper. Marco Trabucchi contributed to the discussion and preparation of the manuscript. Alessandro Padovani contributed to the discussion and preparation of the manuscript

\section{References}

American Psychiatric Association (1994). Diagnostic and Statistical Manual of Mental Disorders, 4th edn. Washington, DC: American Psychiatric Association.

Bellelli, G. et al. (2005). Results of a multi-level therapeutic approach for Alzheimer's disease subjects in the "real world" (CRONOS project): a 36-week follow-up study. Aging - Clinical and Experimental Research, 17, 54-61.

Blazer, D., Hughes, D. C. and George, L. K. (1987). The epidemiology of depression in an elderly community population. Gerontologist, 27, 281-287.

Bruce, M. L., Seeman, T. E., Merrill, S. S. and Blazer, D. G. (1994). The impact of depressive symptomatology on physical disability: MacArthur Studies of Successful Aging. American Fournal of Public Health, 84, 17961799.

Cassano, G. B., Puca, F., Scapicchio, P. L. and Trabucchi, M. (2002). Italian Study Group on Depression in Elderly Patients: paroxetine and fluoxetine effects on mood and cognitive functions in depressed nondemented elderly patients. Fournal of Clinical Psychiatry, 63, 396-402.

Constant, E. L. et al. (2005). Effects of sertraline on depressive symptoms and attentional and executive functions in major depression. Depression and Anxiety, 21, $78-89$.

Cummings, J. L. et al. (1994). The Neuropsychiatric Inventory: comprehensive assessment of psychopathology in dementia. Neurology, 44, 2308-2314.
Fioravanti, M. et al. (1994). The Italian version of the Alzheimer's Disease Assessment Scale, ADAS: psychometric and normative characteristics from a normal aged population. Archives of Gerontology and Geriatrics, 19, 21-30.

Folstein, M. F., Folstein, S. E. and McHugh, P. R. (1975) "Mini-mental state": a practical method for grading the cognitive state of patients for the clinician. Fournal of Psychiatric Research, 12, 189-198.

Harmer, C. J., Bhagwagar, Z., Cowen, P. J. and Goodwin, G. M. (2002). Acute administration of citalopram facilitates memory consolidation in healthy volunteers. Psychopharmacology, 163, 106-110.

Hughes, C. P., Berg, L., Danziger, W. L., Coben, L. A. and Martin, R. L. (1982). A new clinical scale for the staging of dementia. British fournal of Psychiatry, 140, 566-572.

Kalayam, B. and Alexopoulos, G. S. (1999). Prefrontal dysfunction and treatment response in geriatric depression. Archives of General Psychiatry, 56, 713718.

Katz, S., Downs, T. D., Cash, H. R. and Grotz, R. C. (1970). Progress in development of the index of ADL. Gerontologist, 10, 20-30.

Lawton, M. P. and Brody, E. M. (1969). Assessment of older people: self maintaining and instrumental activities of daily living. Gerontologist, 9, 179-186.

Levkovitz, Y. et al. (2002). The SSRI drug fluoxetine, but not the noradrenergic tricyclic drug desipramine, improves memory performance during acute major expression. Brain Research Bulletin, 58, 345-350

McKhann, G. et al. (1984). Clinical diagnosis of Alzheimer's disease. Report of the NINCDS-ADRDA work group under the auspices of the Department of Human Services Task Force on Alzheimer's Disease. Neurology, 34, 939-944.

Morse, L. J., Payton, S. M., Cuny, G. D. and Rogers, J. T. (2004). FDA-preapproved drugs targeted to the translational regulation and processing of the amyloid precursor protein. Fournal of Molecular Neuroscience, 24, 129-136.

Niederehe, G., Burt, D. B. and Zembar, M. J. (1995). Depression and memory impairment: a meta-analysis of the association, its pattern, and specificity. Psychological Bulletin, 117, 285-305.

Pákáski, M. et al. (2005). Imipramine and citalopram facilitate amyloid precursor protein secretion in vitro. Neurochemistry International, 47, 190-195.

Pelton, G. H. et al. (2008). Randomized double-blind placebo-controlled donepezil augmentation in antidepressant-treated elderly patients with depression and cognitive impairment: a pilot study. International fournal of Geriatric Psychiatry, 23, 670-676.

Rapaport, M. H., Schneider, L. S., Dunner, D. L., Davies, J. T. and Pitts, C. D. (2003). Efficacy of controlled- release paroxetine in the treatment of late-life depression. Fournal of Clinical Psychiatry, 64, 10651074

Rocca, P. et al. (2005). Citalopram versus sertraline in late-life nonmajor clinically significant depression: a 1-year follow-up clinical trial. Fournal of Clinical Psychiatry, 66, 360-369. 
Rozzini, L., Vicini Chilovi, B., Bellelli, G., Bertoletti, E., Trabucchi, M. and Padovani, A. (2005). Effects of cholinesterase inhibitors appear greater in patients on established antihypertensive therapy. International fournal of Geriatric Psychiatry, 20, 547-551.

Rozzini, L., Vicini Chilovi, B., Bertoletti, E., Trabucchi, M. and Padovani, A. (2007). Acetylcholinesterase inhibitors and depressive symptoms in patients with mild to moderate Alzheimer's disease. Aging Clinical Experimantal Research, 19, 220-223.

Savaskan, E., Müller, S. E., Böhringer, A., Schulz, A. and Schächinger, H. (2007). Antidepressive therapy with escitalopram improves mood, cognitive symptoms, and identity memory for angry faces in elderly depressed patients. International fournal of Neuropsychopharmacology, $13,1-8$.
Sheikh, J. I. and Yesavage, J. A. (1986). Geriatric Depression Scale (GDS): recent evidence and development of a shorter version. In T. L. Brink (ed.), Clinical Gerontology: A Guide to Assessment and Intervention (pp. 165-173). New York: The Haworth Press

SPSS (2002). Statistical Package for the Social Sciences for Windows Release 11.5.1 (Italian version). Chicago: SPSS Inc.

Suh, G. H. and Shah, A. (2001). A review of the epidemiological transition in dementia: cross-national comparison of the indices related to Alzheimer's disease and vascular dementia. Acta Psychiatrica Scandinavica, 104, $4-11$.

Vythilingam, M. et al. (2004). Hippocampal volume, memory, and cortisol status in major depressive disorder: effects of treatment. Biological Psychiatry, 56, 101-112. 